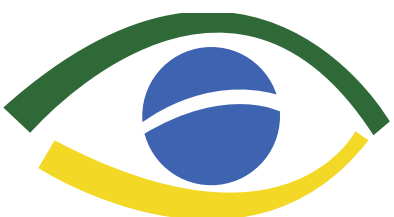

\section{Observatório da Jurisdiçãc Constitucional}

\title{
Implementação qualitativa da educação infantil como fruto da gestão democrática: análise crítica e propostas à luz da ponderação no caso em concreto
}

Luiz Henrique Batista de Oliveira Pedrozo*

Resumo: $O$ presente trabalho tem por objetivo promover uma análise crítica acerca da responsabilização dos Municípios com relação à efetivação de políticas públicas voltadas à educação infantil. Para tanto, se utiliza da análise de caso, para demonstrar como o ente público vem sendo cobrado pelo Poder Judiciário e como a adoção de medidas programáticas e progressivas, de forma dialógica com os atores sociais, em especial, o Ministério Público, podem viabilizar um melhor planejamento das políticas públicas voltadas à educação básica, evitando-se, assim, intervenção posterior, via decisões judiciais, no orçamento Municipal.

De igual maneira, aborda como tem se dado o processo de municipalização dessas políticas públicas, explicando como o acesso à creche e à pré-escola evoluiu desde a promulgação da Constituição Federal de 1988, passando do estágio de uma política assistencialista direcionada prioritariamente à mulheres pobres, até alcançar o status de direito fundamental a ser garantido a toda e qualquer criança de 0 a 5 anos, chamando a atenção, ainda, para o fato de o Ministério Público, ter de rever também, a sua forma de atuação, vez que tem desempenhado parcialmente o seu papel com relação à efetivação qualitativa dessas políticas públicas, concentrando-se na atuação quase que exclusiva de fiscalizar os atos da administração pública posteriores à definição das estratégias e dos orçamentos, quando na verdade deveria se dedicar à participar ativamente do processo de elaboração e planejamento da política pública, inclusive, junto aos conselhos de direito.
Palavras-chave: Educação Infantil; Municipalização; Creches.

Abstract. This work aims at providing a critical analysis about the accountability of municipalities with respect to the effectiveness of early childhood education focused on public policy. For that, it uses case analysis to demonstrate how the public entity has been charged by the judiciary and how the adoption of programmatic and progressive measures, dialogic way with social actors, in particular the prosecutor, may enable a aimed at better planning of basic education policies, thus avoiding, posterior intervention through judicial decisions, the Municipal budget.

Similarly, discusses how has given the process of municipalization of these public policies, explaining how access to daycare and preschool evolved since the enactment of the 1988 Federal Constitution, passing the stage of a welfare policy directed primarily to poor women until it reaches the status of a fundamental right to be guaranteed to any child 0-5 years calling attention also to the fact that the prosecution, having to also revise the way it operates, it has played partially their role in relation to the qualitative effectiveness of these policies, focusing almost exclusively on the role of supervising the acts of subsequent government the definition of strategies and budgets, when he should devote to actively participate in the drafting process planning and public policy, including, along with the right advice.

Keywords. Childhood Education; municipalization; children center.

* Diretor de Pareceres junto à Procuradoria Geral do Município de Ibiporã/PR. Mestrando em Teorias da Justiça e Exclusão na Universidade Estadual do Norte do Paraná (UENP). 


\section{Introdução}

O trabalho em questão tem como ponto de partida, decisão judicial proferida em Ação Civil Pública com preceito cominatório de obrigação e pedido de antecipação de tutela, Processo no 3838-97.2013.8.16.0090, promovida pelo Ministério Público do Estado do Paraná em face do Município de Ibiporã, embasada em dados fornecidos pelo IBGE acerca da taxa bruta de natalidade e em reivindicações diretas feitas por munícipes ao Parquet para obtenção imediata de mais de 340 vagas em creches municipais.

Através da análise de caso, visa-se demonstrar, quais as principais dificuldades enfrentadas pelo ente Municipal para promover de forma indiscriminada e universal uma educação básica ideal, tal qual exige a Constituição Federal, e por quais motivos, atores sociais, a exemplo do Ministério Público, ao invés de participarem ativamente do processo de elaboração e definição dessas políticas públicas, tem preferido permanecer na retaguarda, consentindo ainda que indiretamente que o gestor público mantenha em suas mãos a obrigação de definir as estratégias necessárias à implementação da política pública no Município, focando-se na fiscalização posterior, apontando falhas, exigindo soluções e, invocando uma luta pela implementação das políticas públicas educacionais que a bem da verdade deveria ter sido assumida desde o seu nascedouro, quando da definição do orçamento público para tal fim.

Para tanto, parte do pressuposto de que a educação é um processo de construção continuada do homem em sociedade, necessário à integração de todas as relações interpessoais firmadas no decorrer de sua existência, e que depende, por sua vez, da articulação entre Administração Pública e demais atores sociais, em especial, sociedade civil organizada, Ministério Público e Poder Judiciário, na forma de definições estratégicas de política pública em total consonância com a realidade social.

Objetiva-se, assim, lançar a lume discussão acerca da co-culpabilidade dos demais atores sociais nas falhas que vez ou outra são apontadas no processo de implementação das políticas públicas educacionais por parte dos Municípios, e como a abertura de canais de participação nos processos administrativos que antecedem a definição dessas políticas públicas de educação básica podem proporcionar uma maior eficiência do serviço público.

Nesse sentido, se aposta que as mais acertadas decisões governamentais são aquelas elaboradas em conjunto com segmentos representativos da sociedade, os chamados atores sociopolíticos, e que é preciso ponderação do magistrado para não atribuir exclusivamente ao ente público a insuficiência dos atos por ele praticados em prol da efetivação da política pública educacional, reconhecendo-se os esforços empregados apesar de todas as limitações financeiras, estruturais e político-administrativas. 


\title{
2. A municipalização do ensino
}

A Constituição Federal de 1988, no intuito de promover a estabilidade social e política, trouxe várias mudanças ao cenário social brasileiro, dentre eles, a redefinição do pacto tributário, o fortalecimento e a redefinição do papel das instituiç̧̃̃es e a submissão de todas elas e de todas as autoridades públicas àquilo que denominou claramente, como sendo garantias e direitos fundamentais dos cidadãos. Um desses direitos fundamentais é justamente o acesso à educação de qualidade, que o Estado foi obrigado a rever e promover ao cidadão, desde a sua tenra infância.

Segundo o Plano Nacional de Educação:

\begin{abstract}
A Educação Infantil estabelece as bases da personalidade humana, da inteligência, da vida emocional, da socialização. As primeiras experiências da vida são as que marcam mais profundamente a pessoa. Quando positivas, tendem a reforçar ao longo da vida, as atitudes de autoconfiança, de cooperação, solidariedade, responsabilidade (PNE, 2001/2010).
\end{abstract}

Na busca pelo desejado Estado Democrático de Direito, a Magna Carta ampliou os raios de atuação do Poder Público e promoveu a extensão das políticas públicas a todos os cidadãos. Assim, a educação básica, que antes era direcionada exclusivamente ao atendimento das necessidades das mães pobres que não detinham condições de promover os devidos cuidados aos seus filhos por terem de trabalhar e sustentar a família, passou a ser direito fundamental de toda e qualquer criança na faixa etária de 0 (zero) a 5 (cinco) anos. Não é por acaso, que o capitulo da Constituição Federal dedicado à Educação, mais precisamente o artigo 208, inciso IV, definiu expressamente que o dever do Estado com a Educação será efetivado mediante garantia de "educação infantil, em creche e pré-escola às crianças de até 5 (cinco) anos de idade", o que é repetido no artigo 54, inciso IV, da Lei n 8.069/1990 (Estatuto da Criança e do Adolescente).

Porém, foi com o artigo 211 da Constituição Federal, que dispõe que a União, os Estados, o Distrito Federal e os Municípios organizarão em regime de colaboração os seus sistemas de ensino, cabendo aos municípios atuarem com prioridade no ensino fundamental e na educação infantil, que a tese da descentralização da educação tornou-se efetivamente lei, viabilizando pela primeira vez no Brasil a organização dos sistemas de ensino entre a União, os Estados, o Distrito Federal e os Municípios pela via do chamado Regime de Colaboração, de modo a possibilitar aos Municípios a criação de seus próprios sistemas de ensino, e atribuir a esses autonomia relativa na formulação de políticas educacionais, em específico para a Educação Infantil e o Ensino Fundamental, visto que, até então, a esfera municipal detinha, apenas, o sistema administrativo.

Naquele momento, marcado por fortes reações ao centralismo do regime autoritário e por uma grande revalorização da 
instância local, e apesar da pluralidade de interesses, definiu-se a tendência de atribuição de uma maior autonomia aos Municípios, confirmada, no campo da educação, alguns anos após, pela nova Lei de Diretrizes e Bases da Educação (LDB) Lei no 9.394 -, em 1996. (SOUZA e FARIA, 2004, p. 926).

Mais tarde, esse Regime de Colaboração entre os entes federados (a União, o Distrito Federal, os 27 Estados-membros e mais de 5500 municípios) foi reformulado pela Emenda Constitucional n 14, de 12 de Setembro 1996, que por sua vez viabilizou, , a implantação do Fundo de Manutenção e Desenvolvimento do Ensino Fundamental e de Valorização do Magistério (FUNDEF, hoje denominado FUNDEB), no intuito de promover a descentralização e a otimização dos gastos com educação (CURY, 2000).

Com o advento da CF, foi facultado aos Municípios o direito de emitir normas e a estabelecer políticas, viabilizando, com isto, a implantação do Regime de Colaboração e não mais a manutenção de relações hierárquicas entre as três esferas políticas de poder (União, Estados e Municípios), pelo menos no âmbito da lei. Em que pese a importância da CF nesta matéria, é importante sublinhar que a definição clara de competência dos Municípios para a instituição de seus próprios sistemas de ensino decorre mais das definições prevista na nova LDB $n^{\circ}$ 9394/96, do que naquela Constituição. (SOUZA apud SAVIANI, 2004, p. 930).

No sentido posto acima, a otimização de recursos significa criar condições para uma maior eficiência e, em consequência, maior agilidade e transparência na prestação de serviços públicos pelo Estado, presumindo, ainda, maior envolvimento direto do poder local na captação das demandas, no controle de gastos e na inspeção do cumprimento das metas estabelecidas e, a um só tempo, o acompanhamento dessas ações pelo setor público (MENEZES, 2001).

Porém, tal ideia não se sustenta quando, estatisticamente, se comprova que foi justamente no período após a Constituição Federal que ocorreu no Brasil um fenômeno de multiplicação desordenada de Municípios (em 2003, cerca de $80 \%$ dos Municípios não se sustentavam com receita tributária própria e viam no Fundo de Participação Municipal a principal fonte de renda). E que, multiplicando-se os Municípios, avultaram-se as responsabilidades constitucionais.

Em termos locais, o que se vê, não é a transferência de poder decisório pela União ou Estado ao Município, mas sim, deslocamento de problemas e encargos, vez que os primeiros, em especial a União, continuam a deter percentuais maiores de arrecadação ao passo que redistribuem entre as esferas menores, ou seja, aos Municípios mais responsabilidades.

(...) o Regime de Colaboração entre os sistemas de ensino, de acordo com o modelo em processo de implantação no Brasil, 
vem contrariando os preceitos constitucionais (Artigo $n^{\circ} 211$ da CF de 1988), que apontam para decisões compartilhadas entre sistemas de ensino iguais e autônomos entre si. Tal concepção de colaboração implica igualmente considerar ações conjuntas que abarquem, por exemplo: a divisão de responsabilidades pela oferta do Ensino Fundamental entre as instâncias federadas; o planejamento educacional (planos de educação e censos escolares), de modo a buscar o compromisso comum com a qualidade de ensino; a superação de decisões impostas ou a simples transferência de encargos, sem que haja o repasse devido dos meios e recursos necessários; e, ainda, a garantia de participação da sociedade, através dos seus Conselhos, com representação popular e poder deliberativo (SOUZA e FARIA, 2004, p. 931).

O resultado, apesar dos esforços e de a qualidade do ensino ter melhorado bastante, foi justamente, o decréscimo da participação da União num quadro de elevada desarticulação, o que fomentou a elaboração e a organização de uma educação básica a partir da criação de sistemas de ensinos autônomos, pautados em realidades um tanto quanto diferentes de cada um desses Municípios, promovendo um significativo aumento da desigualdade.

\section{Do cumprimento e do descumprimento das obrigações legais: análise de caso}

\subsection{Uma visão panorâmica da problemática: entender a atuação do município para rever a atuação do ministério público}

No Município de Ibiporã, situado no norte do Estado do Paraná, com aproximadamente 51 (cinquenta e um) mil habitantes, a situação não é diferente dos demais entes municipais. As dificuldades para se atender a crescente demanda por creches ultrapassa as discussões acerca de questões orçamentárias, vai da falta de ações conjuntas capazes de nortear o planejamento familiar, por exemplo, à implementação eficaz de outras políticas públicas não menos importantes, por parte dos outros entes federativos, além da falta de interesse na participação efetiva da política pública por parte da própria sociedade envolvida.

Para se ter uma idéia, quando da elaboração de seu plano plurianual vinculado à participação de recursos públicos, havia previsão para a reforma, construção e ampliação de centros de educação infantil e escolas, perfazendo a previsão de gastos, para 2010, de $\mathrm{R} \$ 439.440,00$ (quatrocentos e trinta e nove mil, quatrocentos e quarenta reais); para 2011, de $R \$ 700.000,00$ (setecentos mil reais); idêntico valor para o ano de 2012 , e para o ano de 2013 , a quantia de $R \$$ $1.000 .000,00$ (um milhão de reais), totalizando a previsão de gastos em $R \$$ 2.839.440,00 (dois milhões, oitocentos e trinta e nove mil, quatrocentos e 
quarenta reais). Na ocasião, foi comunicado o Ministério Público da importância da sua participação na definição do orçamento, porém este não manifestou interesse, cabendo única e exclusivamente aos conselhos municipais definirem as diretrizes ao administrador público.

Neste caso, efetivamente, os investimentos foram bem elevados. A Diretoria de Contabilidade do Município, ao apurar pormenorizadamente os valores aplicados, concluiu que investimentos por parte do Município em Educação Básica foi na escala de $\mathrm{R} \$ 6.248 .907,33$ (seis milhões, duzentos e quarenta e oito mil, novecentos e sete reais e trinta e três centavos), tudo destinado a obras de construção, reforma e ampliação das creches municipais.

Em números de atendimento, isso retratou que, em 2010, o Município atendeu a 210 novas crianças, chamando-as à matrícula nos Centros Municipais de Educação Infantil. Que em 2011, além daquelas já atendidas, outras 536 crianças foram devidamente matriculadas, e ao final de 2012, o número de novos atendimentos havia chegado à casa dos 1.5821, quase dez vezes mais que em 2010 .

Mesmo assim, o Ministério Público promoveu Ação Judicial em face do Município, com o fixo pedido de que o ente público viesse a implementar, em exíguo prazo, 320 (trezentos e vinte) vagas de educação infantil para o atendimento a crianças com idade entre 0 a 5 anos, sob a justificativa de que foram inúmeras as reclamações feitas por mães naquela promotoria, e que o Poder Público Municipal não vinha atendendo a totalidade das demandas por vagas nas creches tal qual exige a Constituição Federal, em seu artigo $6^{\circ}$.

O referido dispositivo erigiu o direito à educação à categoria de direito social, englobando-o à noção de direitos de segunda geração, cuja implementação exige dos poderes públicos municipais prestações positivas a serem realizadas mediante políticas públicas concretizadoras de prerrogativas sociais, destinadas a reduzir desigualdades sociais e a efetivar a garantia do principio fundamental da dignidade da pessoa humana, conforme explicitado no artigo $1^{\circ}$, inciso III, da Constituição Federal.

Em sede de defesa, o Município juntou aos autos cópia do Decreto Municipal $n^{\circ}$ 057/2013, o qual dispõe sobre diretrizes e procedimentos a serem adotados para o cadastramento e matricula de crianças com idade de 04 (quatro) meses a 03 (três) anos, candidatas à vagas em turmas de berçário I e II nas instituições da rede municipal de ensino infantil de lbiporã para comprovar que há regulação, planejamento e definição de critérios objetivos bastante claros a ordenar a educação básica e assim, afastar toda e qualquer alegação no sentido de que houve inadimplência quanto às suas obrigações legais de inserção educacional de infantes.

\footnotetext{
${ }^{1}$ Todos esses dados foram repassados ao Ministério Público quando da instrução do Inquérito Civil por ele motivado.
} 
Neste sentido, procurou reforçar enfaticamente a negativa ao pedido de antecipação de tutela feito pelo Ministério Público, pedido este que já havia sido denegado pelo juízo e que estava sendo reavaliado em sede de agravo de instrumento, embasando-se na necessidade de estrutura adequada e funcionários suficientes para promover todos os atendimentos considerados urgentes, além de esclarecer os riscos que tal medida imporia ao ideal atendimento e a toda sociedade caso houvesse a inserção obrigatória de gastos não previstos no orçamento.

Para tanto, invocou o artigo $2^{\circ}$ da Constituição Federal que trata da separação dos poderes para sustentar a tese no sentido de não competência do Poder Judiciário para atuar em questões afetas à implementação das políticas públicas, considerando tratar-se de poder discricionário marcado pela conveniência e oportunidade, tal qual preceitua a doutrina:

O controle judicial, entretanto, não pode ir ao extremo de admitir que o juiz se substitua ao Administrador. Vale dizer: não pode o juiz entrar no terreno que a lei reservou aos agentes da Administração, perquirindo os critérios de conveniência e oportunidade que the inspiram a conduta. A razão é simples: se o juiz se atém ao exame da legalidade dos atos, não poderá questionar critérios que a própria lei defere ao administrador. Assim, embora louvável a moderna inclinação de ampliar o controle judicial dos atos discricionários, não se poderá chegar ao extremo de permitir que o juiz examine a própria valoração administrativa, legítima em si e atribuída ao administrador. Insta-se, pois, no exame do âmbito dentro do qual pode ser viável a atuação do administrador - situação que se configura com a reserva do possível, vale dizer, o conjunto de elementos a serem sopesados pela Administração, necessários à conclusão da possibilidade ou não do cumprimento de certo objetivo. (CARVALHO FILHO, 2007, p. 44)

Concentrando-se então, em números e estatísticas, a defesa apresentada pelo Município se preocupou em demonstrar ao judiciário, única e tão somente, a ausência de omissão frente à política pública educacional para afastar a efetiva intervenção judicial fundamentada na busca pela execução do direito fundamental, ao passo que, deveria ter levado a baila, também, a real dificuldade para se alcançar o total atendimento das demandas, qual seja, a implementação da gestão democrática das políticas públicas.

Em nenhum momento, procurou-se demonstrar nos autos que a intervenção do Judiciário e do Ministério Público, por exemplo, é considerada bem vinda e necessária à etapa de elaboração e planejamento das políticas públicas educacionais e do orçamento, e que o que deveria ser encarado como sendo imperativo constitucional com relação à participação no processo de elaboração das políticas públicas, vem sendo considerado pelas próprias instituições democráticas, mera liberalidade, prerrogativa ou faculdade. 
Sob essa óptica, percebe-se que o ente municipal, deixou passar uma ótima oportunidade de promover ao julgador, dentro do processo, uma visão panorâmica da problemática aventada, de modo que ao final, ao menos, pudesse exigir pela via inversa, a participação efetiva do Ministério Público nos processos administrativos (que, diga-se de passagem, por precederem a implementação das políticas públicas que estão sob sua responsabilidade, devem ser democráticos).

\begin{abstract}
A política pública é tida, pelo senso comum, como procedimento linear em que fases perfeitamente distintas sucedem-se, de modo a se partir da formação, passando pela implementação, finalizando com a avaliação. É necessário ao jurista o conhecimento do ciclo da política pública para tornar possível o controle jurídico de seu processo e de seus resultados.
\end{abstract}

Desde logo, é preciso ter claro que a política pública dá-se por ciclos, não sendo possível discernir de forma definitiva suas fases, por se verificar um processo de retroalimentação, onde a avaliação não é feita ao final, mas no curso da execução. Isto introduz novos elementos no quadro inicialmente proposto, modificando-o, de forma a adequá-lo à realização do objetivo. (MASSA-ARZABE, 2006, p. 70)

Logicamente, devem existir muitos outros interesses por de traz dessa inércia, tanto por parte da Administração Pública, que prefere manter distância dos canais de participação popular e deliberação democrática das políticas públicas, em nome de uma "pseudo melhor atuação" por parte do gestor, quanto por parte do próprio Ministério Público e do Judiciário, instituições democráticas, que não se interessam, no mais das vezes, em entender como funciona a máquina pública e se interar dos meandros que permeiam o planejamento e o orçamento público. Por entendê-los complexos ou técnicos demais, preferem então, focar suas atuações na fiscalização, ao passo que deveriam ser proativos quando da elaboração das políticas públicas, convocando ou se fazendo presentes em audiências públicas e conselhos gestores, por exemplo, independentemente de serem "convidados" para isso.

Desta feita, ao mesmo tempo em que o alto significado social e o irrecusável valor constitucional de que se reveste o direito à educação básica, que é garantia, por consequência, de proteção à criança, não podem ser menosprezados pelo Estado ante a omissão na implementação e efetivação das políticas públicas eficientes e responsáveis, sob pena de se incorrer em grave e injusta frustração de um compromisso constitucional que visa à preservação dos direitos da população, não pode o Judiciário fechar os olhos para a omissão que recai sob os atores sociais, em especifico o Ministério Público, que tem por obrigação participar ativamente do procedimento de definição dessas políticas públicas, justamente porque é nesta fase que se deve descortinar os prognósticos 
necessários à satisfação adequada do interesse público, que ele próprio Ministério Público fiscaliza.

Sobre o perfil ideal do promotor de justiça junto às políticas públicas, pertinente se faz o seguinte pensamento:

Não será, certamente, aquele que se seduz pelo poder enquanto poder, embora com um novo figurino, mas impregnado de similar coronelismo político, com matreira habilidade midiática na exposição desnecessária de pessoas e valores. E sim o de protagonista de uma nova agenda social composta por políticas públicas efetivamente comprometidas com a doutrina dos direitos humanos. Preocupado em alargar o acesso popular ao Judiciário, trazendo para a arena jurídica um novo jeito de operar o Direito, da ótica das questões realmente relevantes para a sociedade, sob o signo da justiça social, por meio do dístico multifário e difuso ${ }^{2}$. (GIACÓIA, 2007, p. 283).

Sabe-se que nossa sociedade tem pouca cultura política e que esse é um dos desafios mais duros que o país deverá enfrentar para reverter sua condição sócio-política. Porém, é institucional o papel do Ministério Público de atuar proativamente nos diálogos a serem travados entre a sociedade e o Poder Público, principalmente, para evitar que a participação administrativa continue a ser encarada pelos gestores como sendo uma "ciranda de interesses". Contudo, esse tipo de atuação não pode ser concebida a título de prerrogativa, como insiste em afirmar o próprio Ministério Público. É, a bem da verdade, um importante dever.

Dever este que se torna claro, quando se passa a conceber que as demandas (necessidades) são interpretadas por aqueles que ocupam espaços de poder, mas são influenciadas por uma "Agenda", que se cria na sociedade através da pressão política e da mobilização dos diferentes segmentos da sociedade. Cabe, portanto, ao Parquet, auxiliar a sociedade na formação dessa Agenda, mesmo porque política pública não se confunde com programa de governo.

\footnotetext{
${ }^{2}$ Neste sentido, na nítida intenção de expressar a necessidade de que os promotores e procuradores sejam vocacionados, Paulo Bonavides faz a distinção entre os dois Ministérios Públicos do Brasil - o da Constituição e o do Governo: "Com efeito, há dois Ministérios Públicos no Brasil; um é o da Constituição; o outro o do Governo. Um protege os interesses da Sociedade e o povo o aplaude; o outro serve aos fins de quem governa e o povo o reprova. O primeiro é a efígie da independência e da isenção; advoga a causa social, tutela o bem comum, por isso, recebe os louvores da opinião e do corpo de cidadãos. O segundo, ao revés, se mostra o órgão do status quo, é instrumento submisso do Estado, máquina do governo que o mantém debaixo de seu influxo preponderante. O MP da Constituição é a maioria, a legitimidade, o colegiado da cidadania. O do Governo é a minoria, a omissão, o engavetamento, a absência, a deserção nos graves momentos constitucionais de crise do regime. Um é enaltecido, o outro menosprezado. Aquele zela pela moralidade pública em todos os distritos da governança política; este se rebaixa ao grau de servilismo, instrumento inferior do Poder Executivo, o qual the nomeia o Chefe, em ordem a configurar, pelos laços da sujeição estabelecida, o vício institucional gerador de toda essa ruptura, que é a guerra civil interna nos quadros do Ministério Público, responsável do divórcio entre a cúpula e as bases. Um guarda a liberdade, a Constituição, a moral administrativa; o outro faz-se serventuário dos desígnios executivos e se acolhe à sombra do paço presidencial onde cultiva a intimidade do poder". (BONAVIDES, 2003, p. 383-385).
} 
Políticas Públicas são os meios de planejamento para a execução dos serviços públicos, correspondem claramente à função de planejamento, ao passo que, as obras e serviços públicos, caracterizam justamente a execução material dessa função (SANTIN, 2006, p. 35). Assim, se a execução material do que foi planejado não se mostra satisfatório, o Poder Judiciário tem que buscar na fonte dessas políticas públicas os subsídios necessários à punição do gestor, inclusive, por improbidade, e obter meios para que sejam prestados qualitativamente os serviços públicos à população.

(...) políticas públicas são aqui entendidas como o "Estado em ação". Ação, não é, contudo, sinônimo de atividade. É uma ação sistemática e qualificada, de um determinado governo, com o objetivo específico de intervir em contextos sociais, específicos a fim de promover a inclusão. Isso faz com que as políticas guardem profunda relação com as políticas. (ALVES, 2010, p. 213).

Há de se compreender, portanto, que o Ministério Público deve rever sua atuação e promover ações no campo preventivo, ainda que fora de gabinete ou para além do expediente regular de trabalho, promovendo audiências públicas, reuniões diversas, trabalhos em rede, entre outras (NUNES, 2012). Servindo não somente como órgão fiscalizador, mas articulador junto à Administração Pública para garantir ao cidadão, no caso, crianças, o acesso à educação de qualidade.

\begin{abstract}
A participação do Ministério Público na elaboração das políticas públicas passa, em primeiro plano, pelo conhecimento da realidade de cada um dos Municípios, Estados e da União no que concerne ao atendimento dos direitos sociais, buscando, em conjunto com os Poderes Executivo e Legislativo, Conselhos de Gestão e sociedade civil organizada definir prioridades a fim de que eventuais falhas nesse atendimento sejam devidamente corrigidas, indicando a melhor forma de fazer com que os orçamentos públicos contemplem recursos suficientes para tanto. (GONÇALVES, 2009, p. 26).
\end{abstract}

Neste vértice, fica difícil falar em eficiência nas ações de fiscalização promovidas pelo Ministério Público, se este não mantém contatos periódicos com os atores sociais ligados à educação no Município, não realiza reuniões junto aos conselhos ligados à política de educação ou não promove parcerias com outros órgãos de controle, feito o Tribunal de Contas por exemplo.

\title{
3.2 Da natureza prestacional do direito à educação face à compatibilização entre o mínimo existencial e a reserva do possível
}

Entende-se por mínimo existencial (legado constitucional) a teoria que norteia o estabelecimento das metas prioritárias dentro do orçamento público na formulação e execução das políticas públicas, de forma que, só depois de serem 
disponibilizados os recursos necessários, é que serão discutidas as demandas que merecem atendimento.

Porém, a limitação fática e jurídica invocada como justificativa para a não efetivação dos direitos fundamentais prestacionais é que tem recebido a denominação de reserva do possível, segundo a qual, deve sempre existir uma reserva orçamentária para garantir as necessidades públicas básicas da coletividade, a qual não pode ser afetada para o custeio de despesas específicas de um ou mais cidadãos individualmente.

No caso em comento, o juiz da causa, seguindo essa linha de raciocínio, entendeu que a cláusula de reserva do possível não se reveste de caráter absoluto, ainda mais quando esbarra em direitos fundamentais inseridos no mínimo existencial. Porém, compreendeu a necessidade de se analisar a proporcionalidade da prestação e a razoabilidade de sua exigência para tonar efetivas as prestações positivas reclamadas do Município, como destacado no trecho abaixo:

\begin{abstract}
(...) não se pode tolerar que a reserva do possível seja utilizada como meio a tornar legitima a negligencia do Estado em viabilizar e tornar efetivas as políticas públicas necessárias ao custeio inerentes aos direitos dos indivíduos ainda em formação. Desculpa genérica para a omissão estatal no campo da efetivação dos direitos fundamentais não poderá ser acatada, ainda mais quando da existência de controvérsias sobre o não desperdício das verbas públicas, sua regular aplicação aos fins para os quais foram orçadas ou mesmo sua desnecessária vinculação a áreas não prioritárias do ponto de vista da efetivação dos direitos fundamentais.
\end{abstract}

Assim, desconsiderou o magistrado o argumento de possível falta de previsão orçamentária especifica para suportar as despesas em relação à criação de novas vagas nas creches municipais, visto que, no decorrer do processo, demonstrou ainda o Ministério Público, que o Prefeito do Município de Ibiporã havia criado por meio das Leis Municipais $n^{\circ} 2.594 / 2013$ e 2.601/2013, duas novas Secretarias Municipais e promovido a inclusão de mais dois cargos no rol da categoria dos cargos comissionados.

Se o município possui recursos financeiros para gerar todos esses novos cargos, deverá dispor de recursos para o investimento e implementação de vagas na educação infantil, visto ser prioridade absoluta garantida pela Constituição Federal.

E mais, em caso de escassez de recursos, caberá ao Município, primeiramente, dispor dos cargos comissionados e dos servidores em estágio probatório, até que se alcance a efetivação integral ao atendimento das políticas públicas prioritárias, definidas no texto constitucional. (trecho da sentença) 
De igual maneira, rechaçou a tese defensiva de que a discricionariedade do Poder Executivo mostrava-se ameaçada, buscando na doutrina moderna a robustez do seu convencimento neste sentido.

[...] discrição administrativa não pode significar campo de liberdade para o administrador, dentre as várias hipóteses abstratamente comportadas pela norma, eleja qualquer delas no caso concreto. Em última instância, o que se está dizendo é o seguinte: o âmbito de liberdade do administrador perante a norma, não é o mesmo âmbito de liberdade que a norma the quer conferir perante o fato. Está se afirmando que a liberdade administrativa, que a discrição administrativa é maior na norma de direito, do que perante a situação concreta. Em outras palavras: que o plexo de circunstancias fáticas vai compor balizas suplementares à discrição que está traçada abstratamente na norma (que podem, até mesmo, chegar ao ponto de suprimi-la) pois é isto que, obviamente, é pretendido pela norma atributiva de discrição, como condição de atendimento de sua finalidade. (MELLO, 2008, p. 36)

Pois bem, sem discordarmos deste entendimento judicial, mais uma vez questionamos: Se o Ministério Público tivesse acompanhado de perto todo o procedimento, inclusive, aquele que deu origem à criação de novos cargos comissionados. Se interado do tramite junto à Câmara Municipal para tais gastos públicos, vez que houve publicidade desses atos legislativos, o desfecho dessa situação poderia ter sido diferente?

Certamente sim. O Ministério Público, dada sua autonomia, possui condições de atuar preventivamente e repressivamente para uma boa aplicação das verbas públicas, e poderia, por exemplo, ter zelado pelo apoio dos conselhos ligados à educação, exigindo os orçamentos detalhados da Educação Básica (porque os orçamentos genéricos dificultam a compreensão da informação, o ideal acompanhamento do procedimento, servindo de subterfúgio para a realização de desvios e fraudes); poderia ter cobrado mais fiscalização e transparência da folha de pagamentos da Secretaria Municipal de Educação; poderia ter acompanhado os trabalhos dos conselhos e auxiliá-los na fiscalização de bens e prestação de serviços ligados à Educação e à movimentação dos recursos do FUNDEB.

A par disso, poderia também ter obstado o direcionamento de verbas públicas para a criação de cargos antes do total adimplemento das obrigações para com a Educação Básica. Mesmo porque, atualmente, além das informações que podem ser obtidas junto às prefeituras, é possível ter acesso sobre muitos dados referentes à educação infantil junto a banco de dados disponibilizados em sites especializados em pesquisas, análises e estatísticas, tais como o do MEC, INEP, IBGE, sites de ONGS, observatórios sociais ou nas próprias Secretarias de Educação. 


\begin{abstract}
O conceito de fiscalização trazido por este art. 30 da CF deve ser estendido à dimensão não só curativa de problemas na prestação dos serviços, mas também e fundamentalmente preventiva, haja vista que ela deve ser permanente, tanto para evitar os problemas que não deseja, como para oportunizar um espaço permanente de participação qualitativa ao atendimento das demandas que buscam os serviços alcançar, revitalizandoos em níveis de eficácia social maximizada. Tal concepção por certo vem ao encontro dos interesses comunitários que dão causa e sentido à prestação dos serviços públicos, com legitimidade renovada pela inclusão e ação social dos seus usuários na conformação conceitual e de respostas às suas necessidades. (LEAL, 2008, p. 18)
\end{abstract}

Neste ponto, por fim, repousa também a importância dos Conselhos de Direito que, diante do insucesso de alguns dos meios de controle do poder, podem surgir como uma nova alternativa a esta função à medida que algumas decisões do Poder Executivo vão sendo submetidas prioritariamente, ao crivo desses órgãos colegiados, promovendo-se uma espécie de prestação continuada de gestão de serviços públicos, na qual o principal interessado tem participação permanente.

\title{
3.3. Da razoabilidade da decisão judicial ante as especificidades do caso concreto
}

Em que pese o Poder Judiciário não ter acolhido a alegação do Município no sentido de que não se pode falar em inadimplemento em relação ao atendimento para a colocação de crianças do Município de Ibiporã em creches e pré-escolas, ele segue entendimento jurisprudencial que considera que a existência de uma lista de espera prova a inobservância do dever legal de disponibilizar nos centros municipais de educação infantil, vagas para todas as crianças de zero a cinco anos.

Da mesma forma, ainda que não tenha feito o juiz da causa, qualquer consideração com relação àquele dever proativo do Ministério Público, exaustivamente abordado neste trabalho, com relação à atuação preventiva do "mau gasto" público, pode-se dizer que a condenação sofrida pelo ente Municipal foi razoável.

Primeiro, tem-se que o magistrado compreendeu a impossibilidade de o Município esgotar a lista de espera alocando de forma imediata toda e qualquer criança que necessitar de vaga nos centros educacionais sem desrespeitar as regras impostas pela Lei em nome da aprendizagem e do estímulo pedagógico. Para tanto, condenou o Município a suprir a demanda reprimida bem como aquela que vier a surgir em todo o seu território, concedendo-lhe, contudo, o prazo de 4 (quatro) anos a contar de 2014, para obedecer um cronograma de 
implantação a ser definido e protocolizado em juízo até a data do dia 31 de março de 2015, cronograma este que deverá ser contemplado no Plano Orçamentário Plurianual subsequente, sob pena de multa cominatória diária, por cada criança que deixar de ser atendida, no valor de $\mathrm{R} \$ 500,00$ (quinhentos reais).

Condenou ainda o Município a realizar uma previsão de recursos necessários à criação e ao aumento do número de vagas nos Centros Municipais de Educação Infantil (CMEI) nas propostas de leis orçamentárias dos anos de 2015 e seguintes - Plano Plurianual, Leis de Diretrizes Orçamentárias e Leis Orçamentárias Anuais -, devendo ainda, quanto as já definidas, promover a alocação e ou remanejamento dos recursos necessários na proposta e ou Lei Orçamentária para 2015, com posterior execução prioritária do orçamento no setor, de acordo com o disposto nos artigos $4^{\circ}$, caput e parágrafo único, alíneas "b", "c" e "d" e 259, parágrafo único, do Estatuto da Criança e do Adolescente (ECA) e Lei Complementar $n^{\circ} 101 / 2000$, sob pena de multa diária de $\mathrm{R} \$ 1.000,00$ (mil reais) - artigo 461, § 5, do Código de Processo Civil combinado com artigo 213 , $2^{\circ}$, do ECA -, ordenando a destinação desse valor ao fundo gerido pelo Conselho dos Direitos da Criança e do Adolescente do Município, nos moldes do artigo 214 do ECA combinado com os artigos 11 e 13 da Lei n 7.347/1985.

Por fim, em hipótese de descumprimento do Município, condenou o ente público a ter de celebrar convênio com creches e escolas particulares, até que todas as crianças que procurem o serviço sejam devidamente matriculadas, com base no artigo 461 e parágrafos, aplicados subsidiariamente, em consonância com os artigos 152 do ECA e 19 da Lei no 7.347/85.

\section{Conclusão}

O processo de descentralização das políticas públicas, através da Municipalização só surtirá bons frutos se viabilizada a governança embasada na participação e democratização da coisa pública, principalmente no que diz respeito à produção de uma gestão territorial de proximidade entre a Administração Pública e instituições sérias, caso do Ministério Público, promovendo-se assim, a incorporação do cidadão ao desenvolvimento local (CARVALHO, 2012).

Isso porque, as dificuldades financeiras, sempre alegadas pelos administradores como justificativa para a baixa amplitude e qualidade dos serviços públicos essenciais, não podem e não devem, de fato, ser encaradas pelo Judiciário como argumento definitivo. Aos olhos do julgador e dos órgãos de fiscalização, a escassez de recursos deve ser encarada como sendo algo diferente da inexistência total e completa de recursos, ao tempo em que as dificuldades devem ser enfrentadas pelo gestor através de uma escolha consciente das prioridades, com alocação adequada de recursos, priorizando, por óbvio, o que a Constituição Federal já sinaliza como objetivos e metas fundamentais (GONÇALVES, 2009). 
É notório que o caminho a ser percorrido em busca da efetiva implementação das políticas públicas voltadas para a garantia dos direitos fundamentais é longo e repleto de dificuldades. Porém, o fim almejado deve ser compartilhado, para que possa ser considerado justo e recompensador, daí a necessidade da mobilização social e do comprometimento dos Poderes do Estado, tendo no Ministério Público um dos seus principais pontos de apoio e de fomento (GONÇALVES, 2009), apontando-se uma nova configuração de relação pública e espaço público pautados no diálogo e na interlocução democrática entre todos os interessados, oportunizando-se que a ação pública esteja fundada em políticas públicas resultantes de um processo comunicativo voltado ao entendimento dos sujeitos sociais (LEAL, 2008).

\section{Referências Bibliográficas}

ALVES, Fernando de Brito. Constituição e Participação Popular. Porto Alegre: Editora Núria Fábris, 2012.

CARVAlHo, J. M. de. Cidadania no Brasil: o longo caminho. $15^{\circ}$ Ed. Rio de Janeiro: Civilização Brasileira, 2012.

CARVALHO FILHO, José dos Santos. Manual de direito administrativo. 17. ed. Rio de Janeiro: Lumen Juris, 2007.

CURY, C. R. J. Legislação educacional brasileira. Rio de Janeiro: DP\&A, 2000.

GIACÓIA, Gilberto. Ministério Público vocacional. Revista Justitia. São Paulo, n. 197, p. 279-286: Ministério Público de São Paulo - Associação Paulista do Ministério Público, 2007.

GONÇALVES, Leonardo Augusto. O Ministério Público e a busca pela inclusão social: atuação no âmbito das políticas públicas. Anais do XVIII Congresso Nacional do CONPEDI, São Paulo -SP, novembro de 2009.

SANTIN, Valter Foleto. Controle Judicial da Segurança Pública: eficiência do serviço na prevenção e pressão ao crime. Revista dos Tribunais. São Paulo. 2006.

SAVIANI, Demerval. Sistemas de ensino e planos de educação: o âmbito dos municípios. Educação \& Sociedade, Campinas, SP, v. 20, n. 69, p.119-136, dez. 1999.

SOUZA, Donaldo Bello de e FARIA, Lia Ciomar Macedo de. Reforma do estado, descentralização e municipalização do ensino no Brasil: a gestão política dos sistemas 
públicos de ensino pós-LDB 9.394/96. Ensaio: aval.pol.públ.Educ. [online]. 2004, vol. 12, n.45, pp. 925-944. ISSN 0104-4036.

LEAL, Rogério Gesta. O controle jurisdicional de políticas públicas no Brasil: possibilidades materiais. In: SARLET, Ingo Wolfgang. Jurisdição e direitos fundamentais, Volume I, Tomo I. Porto Alegre: Livraria do Advogado, 2005.

LEAL, Rogério. O controle social dos serviços públicos no Brasil como condição de sua possibilidade. Salvador: Revista Eletrônica de Direito do Estado. Instituto Brasileiro de Direito Público, 2008.

MASSA-ARZABE, Patrícia Helena. Dimensão jurídica das políticas públicas. In: BUCCl, Maria Paula Dallari (org.). Políticas públicas: reflexões sobre o conceito jurídico. São Paulo: Saraiva, 2006.

MELLO, Celso Antônio Bandeira de. Discricionariedade e Controle Jurisdicional. Biblioteca do Advogado. Editora Malheiros. $2^{\mathrm{a}}$ edição. $9^{\mathrm{a}}$ tiragem. 2008.

MENEZES, R. M. Processo de gasto e descentralização na política educacional brasileira. Em: Aberto, Brasília, DF, v. 18, n. 74, p. 58-71, dez. 2001.

NUNES, Antônio Carlos Ozório. O Ministério Público e algumas contribuições possíveis à qualidade da educação. Ministério Público do Estado de São Paulo: 01 de ago. de 2012. Disponivel em: http://www.apmp.com.br/index.php/artigos/486-o-ministerio-publico-ealgumas-contribuicoes-possiveis-a-qualidade-da-educacao-dr-antonio-carlos-ozorionunes-assessor-da-area-de-educacao-cao-civel-mp-sp.

\section{Legislação, Jurisprudência e Documentos}

BRASIL. Constituição da República Federativa do Brasil, 1988. Diário Oficial da União, 5 out. 1988, atualizada em julho de 2014. Disponível em: www.planalto.gov.br/ccivil_03/constituicao.htm>Acesso em: 23 set. 2014.

BRASIL. Lei no 9.394, de 20 de dezembro de 1996 - Lei de diretrizes e bases da educação. Diário Oficial da União, 23 dez. 1996. Disponível em: < portal.mec.gov.br/seed/arquivos/pdf/tvescola/leis/lein9394.pdf>Acesso em: 27 ago. 2011.

BRASIL. Ministério da Educação. Programa de Fortalecimento dos Conselhos Escolares cadernos 01 a 10. SEB/MEC, Brasília: 2004. Disponíveis no site: http://portal.mec.gov.br/index.php?option=com_content\&view=article\&id=12384\&ltemi $\mathrm{d}=655$. 
FNPE/CNPG/Foncaije. Cartilha: Subsídios ao Ministério Público para acompanhamento do FUNDEB - Fundo Nacional de Desenvolvimento da Educação. Disponível no site: http://www.fnde.gov.br.

Artigo recebido em 08 de outubro de 2014. Artigo aprovado para publicação em 10 de dezembro de 2014.

DOI: $10.11117 / 1982-4564.07 .17$ 